\title{
A Pedagogical Game Design Document (Ped-GDD) to Promote Teachers' Engagement in the Kingdom of Saudi Arabia
}

\author{
Saggah, Alaa ${ }^{1,2[0000-0001-6650-2028]}$, Atkins, Anthony ${ }^{1[0000-0002-8447-4822]}$ and Campion, \\ Russell 1[0000-0001-5566-876X] \\ ${ }^{1}$ Staffordshire University, Stoke on Trent ST4 2DE, UK \\ ${ }^{2}$ Umm Al-Qura University, Makkah, Kingdom of Saudi Arabia \\ lncsespringer.com
}

\begin{abstract}
Current research suggests that using gamification in a pedagogical context can provide a positive learning experience to students. Integrating teachers' pedagogical input into the early stage of game design is an understudied area, and although the teachers' role is acknowledged, the way of communicating teachers' input is still undetermined. The current literature suggests the practice of using a Gamification Design Document (GDD) to illustrate a game requirements plan is a useful approach. In this paper, we discuss the development of a Pedagogical Game Design Document (Ped-GDD) using an Agile Holistic Framework to Support Teachers in Pedagogical Gamification Design. The paper also suggests the benefits of extending the research of the Ped-GDD further to be part of an e-Government scheme in the Kingdom of Saudi Arabia (KSA) to promote resources collaboration amongst teachers in educational software tool developments.
\end{abstract}

Keywords: Gamification, Pedagogical Game Design Document, Educational games, E-government, Kingdom of Saudi Arabia.

\section{Introduction}

Current literature suggests that gamification can promote students' engagement and and influence their experience positively [1], [2], [3]. This paper discusses the development of a Pedagogical Game Design Document (Ped-GDD) using an Agile Holistic Framework to Support Teachers in Pedagogical Gamification Design (AH-PGD) which is illustrated in Figure 1. The framework is composed of four distinct stages: Stage 1 Requirements; Stage 2 Gamification design; Stage 3 Implementation; and Stage 4 Testing and evaluation. The focus of this research is the Gamification design (which is shown as the second stage in Figure 1). The process of developing the framework elements and sub-elements has been documented in earlier research [4], [5] and [6]. The aim of Ped-GDD is to facilitate communication among teachers and game developers. 
For future work, it is proposed to develop this concept as part of e-Government implementation for educational software tools development to promote teaching collaboration on a national level in the Kingdom of Saudi Arabia (KSA) which will contribute to a dramatic improvement in resourcing and help improve educational support to teachers and educational institutions in KSA.

This paper is organized as follows: Section 2 discusses the previous related work and provides a literature review. Section 3 outlines the Pedagogical Games Design Document (Ped-GDD) and gives an example of its application for teaching English in a school environment. Finally, the conclusion and proposed future work are presented in Section 4.

\section{Related work/Literature review}

\subsection{Pedagogical Gamification}

Previous work suggests [4] a collaborative approach to facilitate teacher engagement in the design process of gamification and enable a better fit for pedagogic requirements. Teachers recognize the importance of collaboration with game developers in turning the conceptual design into an electronic game for teaching purposes [6]. However, the form of communication between teachers and game developers was yet to be determined. The paper proposes a template that can be used to communicate the pedagogical input of teachers to the game developers to help facilitate collaboration to achieve a pedagogical gamification approach. The template will contain an example of an educational game requirements list for a particular lesson. The intention is for the teacher to be able to use that example to convey the gamification concept into their choice of educational material, as outlined in Section 3 of this paper. Consequently, the AH-PGD Framework Stage 2 Gamification design template with associated elements as illustrated in Figure 1, will be used to assist teachers in communicating with games developers. The next section will discuss the current GDDs which are templates generated for games in general, while this paper aims to develop a GDD that also serves pedagogical purposes from a teaching perspective. 


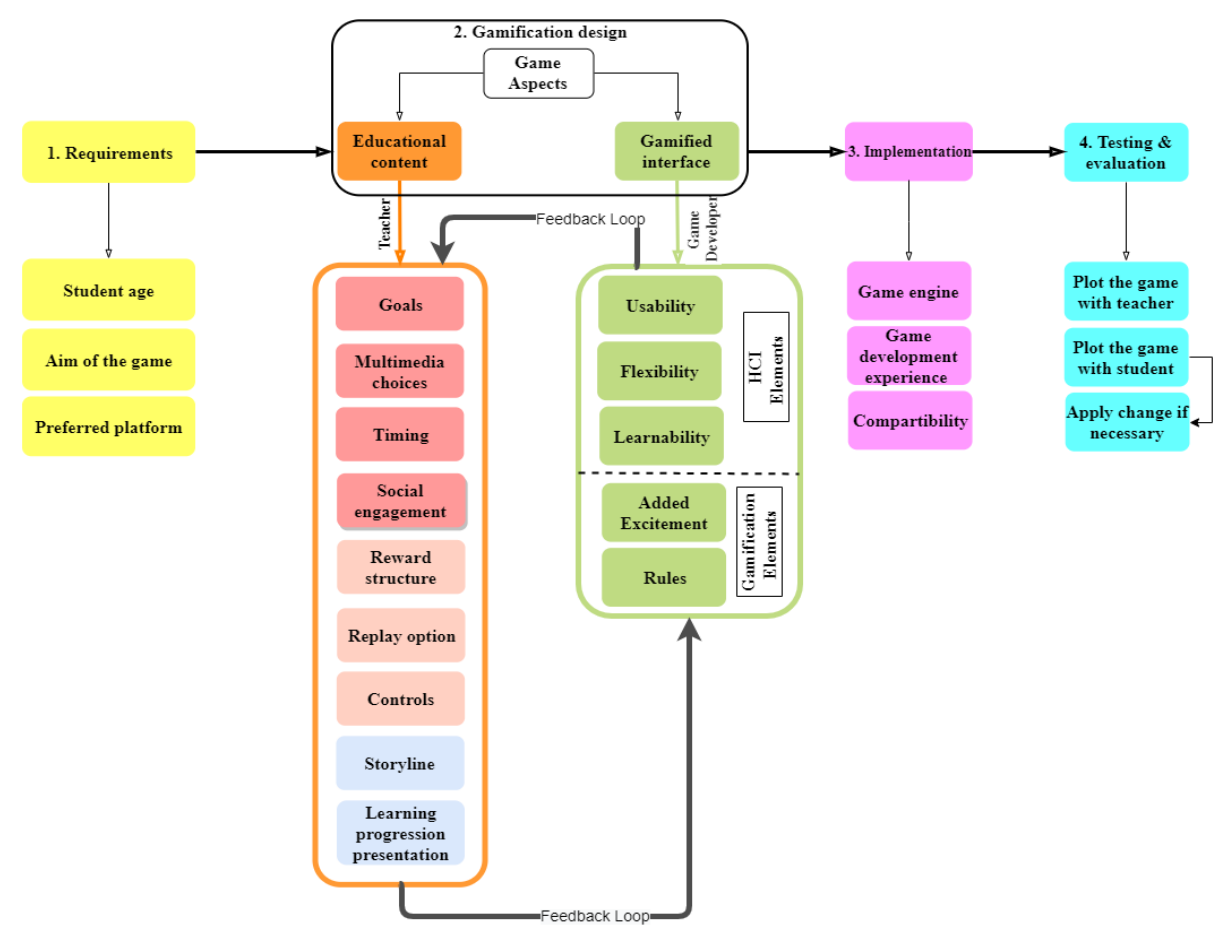

Fig. 1. An Agile Holistic Framework of Pedagogical Gamification Design (AH-PGD)

\subsection{Game Design Document (GDD)}

The current literature identifies a Game Design Document (GDD) as a template used in the game development industry to gather game requirements [7-8-9-10, 11]. The developed AH-PGD Framework has eleven gamification elements that are mapped to the current GDD components outlined in Table 1. One of the challenges of the current GDD to teachers is the use of technical terms, e.g., mechanics, gameplay, dynamics, without further illustration, which might be challenging for teachers to address. The Ped-GDD is designed to accommodate different levels of teachers' computer literacy. Another challenge for teachers is the inclusion of commercial and business aspects, e.g., marketing, which is applicable in [10].

There are similar elements amongst the Ped-GDD and the current GDDs with differences in the wording with the meaning remained the same. For example, Goals in this Ped-GDD was referred to as objectives by [7], as a milestone by [9], challenge by [10], as illustrated in Table 1. Another example of Social engagement in Ped-GDD is referred to as enemies by [7, 8], team size by [9], as illustrated in Table 1 .

The overall number of gamification elements studied in Ped-GDD is eleven. The number of elements that were mapped to the existing GDD and the equivalent ranged from one to seven, as illustrated in Table 1. Ped-GDD has eleven gamification elements 
that include some sub-elements built into the framework from pedagogical consideration, which supports the holistic aspect of the framework.

Table 1. Mapping the proposed Ped-GDD to the existing examples of GDD from the literature

\begin{tabular}{|c|c|c|c|c|c|}
\hline $\begin{array}{l}\text { Gamification elements } \\
\text { (Framework components) }\end{array}$ & GDD [7] & GDD Ten-Pager [8] & GDD template [9] & GDD community [10] & GDD [11] \\
\hline Goals & \begin{tabular}{|l|l|}
$\begin{array}{l}\text { objectives, } \\
\text { challenges }\end{array}$ & levels, \\
\end{tabular} & & Milestone & $\begin{array}{l}\text { Goals, Progression \& } \\
\text { challenge }\end{array}$ & \\
\hline Multimedia choice & $\begin{array}{l}\text { Aesthetic what players } \\
\text { will hear and see }\end{array}$ & & 2D, 3D, sound, animation & Music\& sound, Art style & \\
\hline Timing & & & Time scale & & \\
\hline Social engagement & enemy & Enemies, Multiplayer & Team size & & \\
\hline Reward structure & Rewards & Collectibles, Monetization & & $\begin{array}{l}\text { Losing (as in score } \\
\text { mechanics) }\end{array}$ & \\
\hline \multicolumn{6}{|l|}{ Replay option } \\
\hline Controls & & & & User skills & \\
\hline Storyline & player avatar & Story & Theme, story & $\begin{array}{l}\text { Characters, Story, theme, } \\
\text { Story Progression }\end{array}$ & Core concept \\
\hline $\begin{array}{l}\text { Learning progression } \\
\text { representation }\end{array}$ & & \begin{tabular}{|l} 
Progression \\
\end{tabular} & & Progression \& challenge & \\
\hline Rules & $\begin{array}{l}\text { rules of how elements can } \\
\text { interact with } \\
\text { others }\end{array}$ & $\begin{array}{l}\text { A mechanic is an item or } \\
\text { element that players } \\
\text { interact with to create or } \\
\text { aid with gameplay }\end{array}$ & & & \\
\hline Added excitement & & $\begin{array}{l}\begin{array}{l}\text { Power-ups, bonus } \\
\text { material }\end{array}\end{array}$ & & Items \& powerups & \\
\hline Number of matching & $6 / 11$ & 6/11 & 5/11 & $7 / 11$ & $1 / 11$ \\
\hline
\end{tabular}

\section{Pedagogical Game Design Document (Ped-GDD)}

The Ped-GDD is a document that has two major collaborators, teachers and game developers. Teachers' task encompasses nine elements which are as follows: Goals, Multimedia choice, Timing, Social engagement, Reward structure, Replay option, Controls, Storyline and Learning progression presentation. Each of these nine elements has at least one sub-element, as illustrated in Table 2. The Ped-GDD provided in Table 2 includes an example of a game to teach English letters. 
Table 2. Ped-GDD Illustrative Example of a game to teach English letters

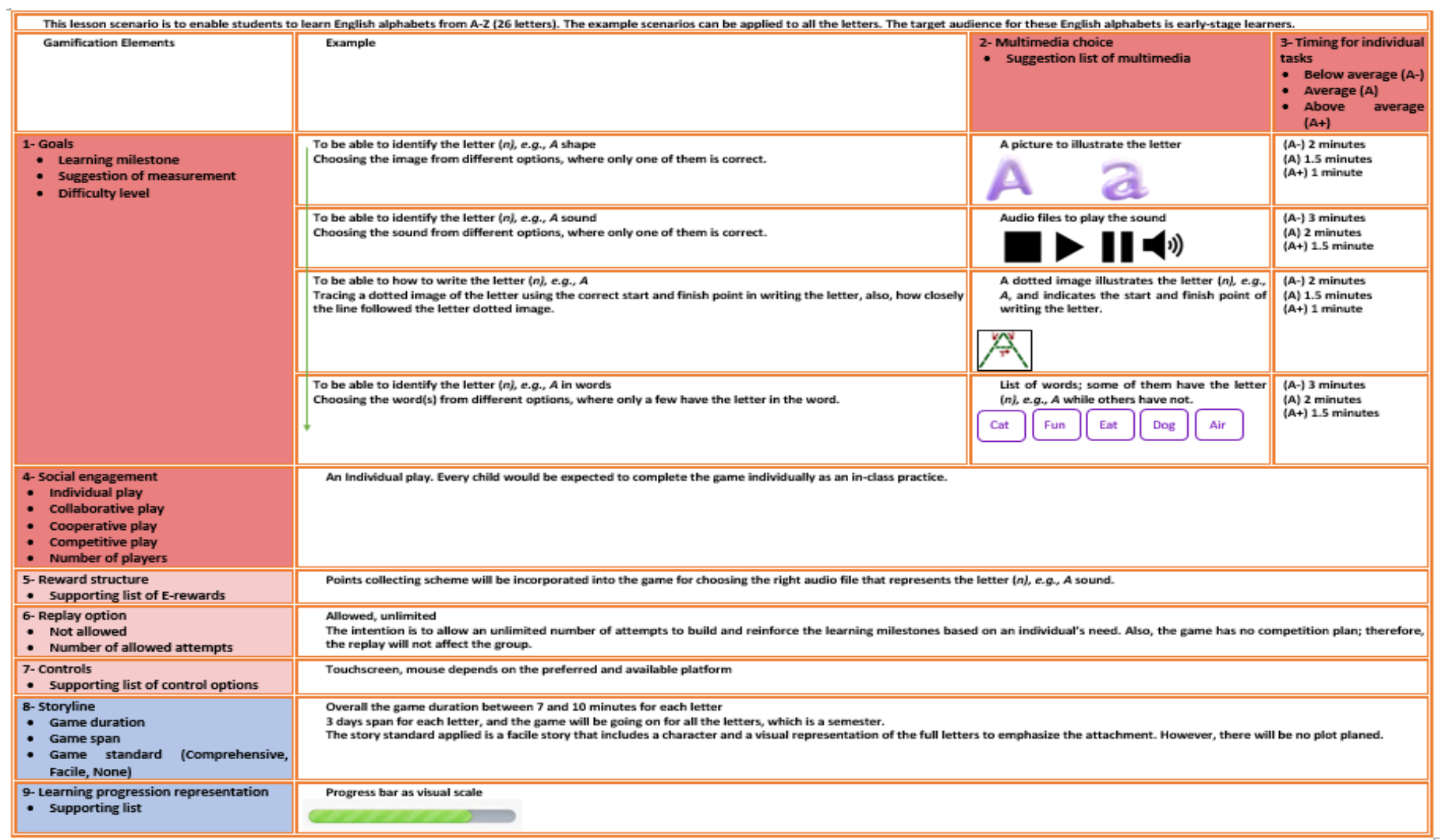




\section{Conclusion}

There is a need to develop a Pedagogical Game Design Document (Ped-GDD) template that facilitates collaboration between teachers and game developers by including pedagogical gamified requirements. A flexible template is required that allows teachers to use the elements collectively or separately while giving game developers a chance to modify and or add the supporting requirements. The Ped-GDD template provides illustrations and examples to simplify the process for the teachers and assure consistency with elements' and sub-elements' meanings.

As research suggests that gamification is 'a modern educational approach' [3], this paper suggests future work to combine the benefits of pedagogical gamification with eGovernment educational initiatives to enable more extensive collaboration amongst teachers nationwide in educational software tools development. The intention is that eGovernment educational initiative from Vision 2030 of Saudi Arabia will also help to build a national repository of Ped-GDD examples of lessons to minimize the effort and maximize the impact and improve resources. The repository will hold the examples of gamification applied to lessons that can be shared and modified without the need to duplicate the effort. Abu-Shanab and Al-Sayed [12] suggested using gamification mechanics such as points or coupons to promote the use of e-Governments amongst citizens. The adoption of technology has been an area of study on emerging technologies, which also applies to e-Government. Alloghani et al. [13] suggest that applying the gamification concept into the e-Government application would help to overcome the technology adoption barrier. Furthermore, [13] mentioned the positive experience of gamification in education on a governmental level, such as providing feedback and allowing better planning for improvements.

\section{References}

1. ter Vrugte J, de Jong T, Vandercruysse S, et al (2015) How competition and heterogeneous collaboration interact in prevocational game-based mathematics education. Comput Educ 89:42-52. https://doi.org/10.1016/j.compedu.2015.08.010

2. Morillas Barrio C, Munoz-Organero M, Sanchez Soriano J (2016) Can Gamification Improve the Benefits of Student Response Systems in Learning? An Experimental Study. IEEE Trans Emerg Top Comput 4:429-438. https://doi.org/10.1109/TETC.2015.2497459

3. Skalka J, Drlik M (2018) Priscilla-Proposal of System Architecture for Programming Learning and Teaching Environment. In: IEEE 12th International Conference on Application of Information and Communication Technologies, AICT 2018 - Proceedings. Institute of Electrical and Electronics Engineers Inc.

4. Saggah A, Campion R, Stanier C (2018) An Investigation of the Role of the Teacher in Gamified Learning in Primary Schools. In: EDULEARN18 Proceedings. IATED Academy, Palma, Mallorca, pp 7700-7708

5. Saggah A, Campion R, Stanier C (2018) A Collaborative Gamification Design Framework in an Educational Context. In: ICERI2018 Proceedings. IATED, Seville, pp 2410-2414 
6. Saggah A, Campion R, Atkins A (2020) An Agile Holistic Framework to Support Teachers in Pedagogical Gamification Design. In: 2019 International Conference on Advances in the Emerging Computing Technologies (AECT). IEEE, Madinah, p (In Press)

7. Salazar MG, Mitre HA, Olalde CL, Sanchez JLG (2012) Proposal of Game Design Document from software engineering requirements perspective. In: 2012 17th International Conference on Computer Games (CGAMES). IEEE, pp 81-85

8. Rogers S (2014) Level up!: the guide to great video game design. John Wiley \& Sons, Chichester

9. Stanley B (2014) Game Design Document Template - Unity Forum. In: Unity Forums. https://forum.unity.com/threads/game-design-document-template.240038/. Accessed 20 Mar 2019

10. Gonzalez L (2016) Gamasutra: Leandro Gonzalez's Blog - How to Write a Game Design Document. In: Gamasutra.com. https://www.gamasutra.com/blogs/LeandroGonzalez/20160726/277928/How_to_Write_a_ Game_Design_Document.php. Accessed 20 Mar 2019

11. gamedesigning.org (2018) How to Create a Game Design Document | In-Depth Guide. https://www.gamedesigning.org/learn/game-design-document/. Accessed 20 Mar 2019

12. Abu-Shanab EA, Al-Sayed MR (2019) Can Gamification Concepts Work With EGovernment? J Inf Technol Res 12:44-59. https://doi.org/10.4018/JITR.2019070103

13. Alloghani M, Hussain A, Al-Jumeily D, et al (2017) Gamification in e-governance: Development of an online gamified system to enhance government entities services delivery and promote public's awareness. In: ACM International Conference Proceeding Series. Association for Computing Machinery, pp 176-181 